\begin{tabular}{|c|l|}
\hline Title & A mperometric Detection of Hydrogen Peroxide U sing InP Porous Nanostructures \\
\hline Author(s) & Sato, Taketomo; Mizohata, A kinori; Y oshizawa, Naoki; Hashizume, Tamotsu \\
\hline Citation & $\begin{array}{l}\text { A pplied Physics Express, 1(5), 051202 } \\
\text { https://doi.org/10.1143/APEX.1.051202 }\end{array}$ \\
\hline Issue Date & 2008-05 \\
\hline Doc URL & http://hdl.handle.net/2115/42587 \\
\hline Rights & ○ 2008 The Japan Society of A pplied Physics \\
\hline Type & article (author version) \\
\hline File Information & APEX1_051202.pdf \\
\hline
\end{tabular}

Instructions for use 


\section{Amperometric Detection of Hydrogen Peroxide using InP Porous Nanostructures}

Taketomo Sato*, Akinori Mizohata, Naoki Yoshizawa, and Tamotsu Hashizume

Research Center for Integrated Quantum Electronics (RCIQE), Graduate School of Information Science and Technology, Hokkaido University, Sapporo 060-8628, Japan

"E-mail address: $\quad$ taketomo@rciqe.hokudai.ac.jp

The electrocatalytic activity of n-type InP porous nanostructures was investigated in terms of their application to amperometric biochemical sensors. The current sensitivities for $\mathrm{H}_{2} \mathrm{O}_{2}$ detection were strongly dependent on the structural properties of these porous nanostructures. A sample with deeper pores responsed more sensitively because of the enlarged surface area inside the nanopores. The removal of an irregular top layer also effectively improved the current sensitivity. The conductive porous nanostructures presented here were very promising for the direct amperometric detection of $\mathrm{H}_{2} \mathrm{O}_{2}$.

Hydrogen peroxide $\left(\mathrm{H}_{2} \mathrm{O}_{2}\right)$ is one of the most important intermediates in various chemical and biological reactions. Therefore, a great deal of research in the past few decades has been devoted to the directly detecting $\mathrm{H}_{2} \mathrm{O}_{2}$ electrochemically to produce stable and high-performance biochemical sensors. One present challenge in biochemical sensor research is to utilize conductive nanomaterials with a large surface area. This approach to achieving high sensitivity in various biochemical sensors is quite practical. To date, various nanomaterials have been investigated for this purpose, such as nanoparticles ${ }^{1,2)}$, carbon nanotubes, ${ }^{3-5)}$ semiconductor nanowires, ${ }^{6,7)}$ conducting polymers ${ }^{8)}$, and porous materials. $^{9,10)}$

Of these, the semiconductor porous nanostructures formed by electrochemical anodization are one of the more promising candidates for the building blocks of biochemical sensors. These porous structures have extremely large surface areas over $10 \mathrm{~m}^{2} / \mathrm{cm}^{3}$ and superior electrical properties with conductive semiconductor substrates. These features are very useful for detecting various electrochemical reactions.

We demonstrated the direct detection of $\mathrm{H}_{2} \mathrm{O}_{2}$ amperometrically by using porous nanostructures formed on highly-doped n-type InP substrates. We recently succeeded in electrochemically forming arrays of straight nanopores on n-InP (001) substrates. ${ }^{11-14)}$ The nanopores were laterally separated by InP nanowalls several tens of nanometers thick, and formed along a straight vertical direction more than several tens of micrometers. In addition to this, n-type InP has attracted attention as a sensor material due to the well-known surface sensitive nature of InP. 
Various gas sensors such as $\mathrm{H}_{2}$ gas sensors ${ }^{15,16)}$ and $\mathrm{NO}_{2}$ gas sensors ${ }^{17)}$ have been recently reported on n-type InP. In this study, we focused on the electrocatalytic activity of the InP porous nanostructures in terms of their application to amperometric biochemical sensors. The current sensitivities for detecting $\mathrm{H}_{2} \mathrm{O}_{2}$ were investigated using various porous electrodes with different structural properties.

The experimental setup and the schematics for the porous electrode are outlined in Fig. 1(a). A series of electrochemical measurements was conducted using a standard cell with three electrodes: an InP porous electrode used as a working electrode (WE), a Pt counter electrode (CE), and a saturated calomel electrode (SCE) used as a reference. All electrodes were dipped into $100 \mathrm{ml}$ of phosphate buffer solution (PBS) with a $\mathrm{pH}$ of 7.4. The potential of WE, $V_{\mathrm{s}}$, with respect to SCE was precisely controlled with a potentiostat with a voltage source.

The porous electrodes were electrochemically prepared as follows. ${ }^{13,14)}$ A (001) n-type InP electrode $\left(\mathrm{n}=1 \times 10^{18} \mathrm{~cm}^{-3}\right)$ was anodized at $4 \mathrm{~V}$ in an electrolyte consisting of $1 \mathrm{M} \mathrm{HCl}(200 \mathrm{ml})$ with $\mathrm{HNO}_{3}(3 \mathrm{ml})$. As previously reported, a disordered irregular layer formed during the initial stage when the pores formed and partly remained on top of the ordered porous layer. Then, to remove the irregular top layer, the porous surface was photo-electrochemically etched at an anodic bias of $1 \mathrm{~V}$ in the same electrolyte under illumination. ${ }^{14)}$ Figures 1 (b) and 1(c) show typical scanning electron microscope (SEM) images of the InP porous sample before and after photo-electrochemical (PEC) etching for 200 s, respectively. As shown in Fig. 1(b), the irregular top layer remained on the straight pore region. The average pore diameter of the sample before the PEC process was about $30 \mathrm{~nm}$. On the other hand, regular sized pores about $130 \mathrm{~nm}$ in diameter appeared on the surface over a wide area after the PEC process. This indicates that the disordered irregular layer was completely removed after the PEC process.

Samples with a different pore depth, $d$, were prepared in this study by changing the anodization time. The current sensitivities for detecting $\mathrm{H}_{2} \mathrm{O}_{2}$ were compared using amperometric measurements. The $V_{\mathrm{s}}$ was set at $+0.65 \mathrm{~V}$ in the dark to enable the $\mathrm{H}_{2} \mathrm{O}_{2}$ to be directly detected. After the background current had stabilized at the WE, amperometric measurements were carried out by successively adding $35 \% \mathrm{H}_{2} \mathrm{O}_{2}$ into a PBS electrolyte. The concentration of $\mathrm{H}_{2} \mathrm{O}_{2}$ is corresponding to $1.14 \mathrm{mM}$ when $100 \mu \mathrm{l}$ of $\mathrm{H}_{2} \mathrm{O}_{2}$ was added in $100 \mathrm{ml}$ of electrolyte.

Figure 2 plots the amperometric response of the InP porous electrode with a pore depth, $d$, of $5.4 \mu \mathrm{m}$. The arrows in the figure indicate the timing when $\mathrm{H}_{2} \mathrm{O}_{2}$ was added to the PBS electrolyte. In comparison, no response current can be observed for the planar electrode in Fig. 2. However, anodic response currents were observed on the InP porous electrode and the currents increased after $\mathrm{H}_{2} \mathrm{O}_{2}$ was added. From the results of cyclic voltammetry, the anodic current started to increase at 
around $0.5 \mathrm{~V}$, which is comparable with the potential of the following reaction.

$$
\mathrm{H}_{2} \mathrm{O}_{2} \rightarrow \mathrm{O}_{2}+2 \mathrm{H}^{+}+2 \mathrm{e}^{-}
$$

This indicates that the electrocatalytic activity of the InP surface was enhanced by the formation of porous nanostructures and the observed response currents were due to the oxidation of $\mathrm{H}_{2} \mathrm{O}_{2}$ described by eq. (1).

We then investigated how sensitive three kinds of porous structures with different pore depths, $d$, were in detecting $\mathrm{H}_{2} \mathrm{O}_{2}$ amperometrically. Figure 3(a) plots the transient curves for anodic currents obtained on a porous electrode with $d=5.4 \mu \mathrm{m}$ with $\mathrm{H}_{2} \mathrm{O}_{2}$ only added once. As expected, the measured current density was strongly dependent on the amount of $\mathrm{H}_{2} \mathrm{O}_{2}$. Furthermore, we found that the response currents reached peak values at the very beginning when $\mathrm{H}_{2} \mathrm{O}_{2}$ was added, then decreased rapidly, and approached various saturation values, as shown in Fig. 3 (a). This kind of behavior on the current transient has not been observed for a planar electrode on a time scale from seconds to minutes. The current transient properties observed here may involve the diffusion process of reactants, such as $\mathrm{H}_{2} \mathrm{O}_{2}$ and $\mathrm{O}_{2}$ inside the very narrow nanopores. As shown in Fig. 2, subsequent response currents considerably decreased after the first adding of $\mathrm{H}_{2} \mathrm{O}_{2}$. This result suggests that the subsequent supply of $\mathrm{H}_{2} \mathrm{O}_{2}$ was inhibited by the residual reactant produced at the first reaction in the nanopores. However, further experimental and theoretical discussions are necessary to clarify the complicated current response observed in the porous electrodes.

Figure 3(b) compares the calibration plots for detecting $\mathrm{H}_{2} \mathrm{O}_{2}$ obtained at electrodes with different $d$ 's of 5.4, 8.1, and $10.2 \mu \mathrm{m}$. The values for current density were measured at $t=20 \mathrm{~s}$ after $\mathrm{H}_{2} \mathrm{O}_{2}$ was added, as indicated by the dashed line in Fig. 3(a). The all data plotted in Fig. 3(b) were calibrated by subtracting zero-offset currents. The amounts of $\mathrm{H}_{2} \mathrm{O}_{2}$ shown in Fig. 3(a) were corresponding to $0.456,0.912,1.37$, and $1.82 \mathrm{mM}$ in terms of concentrations in the electrolyte. All electrodes exhibit good linearity between the current signal and $\mathrm{H}_{2} \mathrm{O}_{2}$ concentration in a range from 0 to $2 \mathrm{mM}$. The correlation coefficients obtained by linear fitting on the experimental data were greater than or equal to 0.996 for all electrodes. As shown in Fig. 3(b), the sensitivity depended strongly on the pore depth. The current sensitivities for detecting $\mathrm{H}_{2} \mathrm{O}_{2}$ are summarized in Table I for various porous electrodes. Samples with large $d$ 's had higher sensitivity than those with small $d$ 's. This is most probably because the effective surface area available for detecting $\mathrm{H}_{2} \mathrm{O}_{2}$ increased with the pore depth. In this study, the highest value of $1.670 \mu \mathrm{A} / \mathrm{mM} \cdot \mathrm{cm}^{2}$ was obtained on a sample with $d=10.2 \mu \mathrm{m}$.

It is also interesting to note that the PEC process after pores had formed extremely effectively improved the sensing properties of the InP porous electrodes, in spite of reduction of total surface area. One explanation for this is that the diffusion coefficient was increased inside the nanopores after the PEC process. As shown in Figs. 1(b) and 1(c), the irregular top layer that partly remained 
on the regular porous structures was completely removed after the PEC process. We believe that the diffusion of reactants into and out of nanopores was enhanced due to the enlarged openings of all pores after the PEC process.

In summary, we investigated the electrocatalytic activity of n-type InP porous nanostructures in terms of their application to amperometric biochemical sensors. The response currents to the addition of $\mathrm{H}_{2} \mathrm{O}_{2}$ increased on the porous electrodes due to their enlarged surface area. The current sensitivity had good linearity with $\mathrm{H}_{2} \mathrm{O}_{2}$ concentration and strongly depended on structural properties such as the pore depth and surface morphology of the porous electrodes.

The work reported here was supported in part by the Ozawa and Yoshikawa Memorial Electronics Research Foundation and by a Grant-in-Aid for young scientists, (B)-19760208, from the Japanese Ministry of Education, Culture, Sports, Science, and Technology.

\section{References}

1) G. Wang, K. Mantey, M. H. Nayfeh, and S. T. Yau: Appl. Phys. Lett. 89 (2006) 243901.

2) Z. W. Zhao, X. J. Chen, B. K. Tay, J. S. Chen, Z. J. Han, and K. A. Khor: Biosens. Bioelectron. 23 (2007) 135.

3) J. A. Nichols, H. Saito, C. Deck, and P. R. Bandaru: J. Appl. Phys. 102 (2007) 064306.

4) Y. Lin, F. Lu, Y. Tu, and Z. Ren: Nano Lett. 4 (2004) 191.

5) F. Qu, M. Yang, G. Shen, and R. Yu, Biosens. Bioelectron. 22 (2007) 1749.

6) Y. Cui, Q. Wei, H. Park, and C. M. Lieber: Science 293 (2001) 1289.

7) Y. Chen, X. Wang, S. Erramilli, P. Mohanty, and A. Kalinowski: Appl. Phys. Lett. 89 (2006) 223512.

8) M. C. B.- López, S. G.- Fernández, M. J. L.- Castanón, A. J. M.- Ordieres, and P. T.- Blanco: Anal. Bioanal. Chem. 378 (2004) 1922.

9) M. S. Salem, M. J. Sailor, F. A. Harraz, T. Sakka, and Y. H. Ogata: J. Appl. Phys. 100 (2006) 083520 .

10) C. A. Betty, R. Lal, D. K. Sharma, J. V. Yakmi, and J. P. Mittal: Sens. Actuators B: Chem. 97 (2004) 334.

11) H. Fujikura, A. Liu, A. Hamamatsu, T. Sato, and H. Hasegawa: Jpn. J. Appl. Phys. 39 (2000) 4616.

12) T. Sato, T. Fujino, and H. Hasegawa: Appl. Surf. Sci. 252 (2006) 5457.

13) T. Sato, T. Fujino, and T. Hashizume: Electrochem. Solid State Lett. 10 (2007) H153.

14) T. Sato and A. Mizohata: to be published in Electrochem. Solid State Lett. 11 (2008).

15) H.-I. Chen, Y.-I. Chou, and C.-Y. Chu: Sens. Actuators B 85 (2002) 10. 
16) T. Kimura, H. Hasegawa, T. Sato, and T. Hashizume: Jpn. J. Appl. Phys. 45 (2006) 3414.

17) K. Wierzbowska, A. Pauly, B. Adamowicz, and L. Bideux: Phys. Status Solidi A 203 (2006) 2281.

Table I: Comparison of sensitivities of different porous electrodes.

\begin{tabular}{ccc}
\hline Electrodes & $\begin{array}{c}\text { Sensitivities } \\
\left(\mu \mathrm{A} / \mathrm{mM} \cdot \mathrm{cm}^{2}\right)\end{array}$ & $\begin{array}{c}\text { Correlation } \\
\text { coefficients }\end{array}$ \\
\hline Porous $(d=5.4 \mu \mathrm{m})$ & 0.536 & 0.997 \\
\hline Porous $(d=8.1 \mu \mathrm{m})$ & 0.780 & 0.999 \\
\hline Porous $(d=10.2 \mu \mathrm{m})$ & 1.670 & 0.996 \\
\hline Porous $(d=16.4 \mu \mathrm{m})$ without PEC process & 0.088 & 0.993 \\
\hline \hline
\end{tabular}

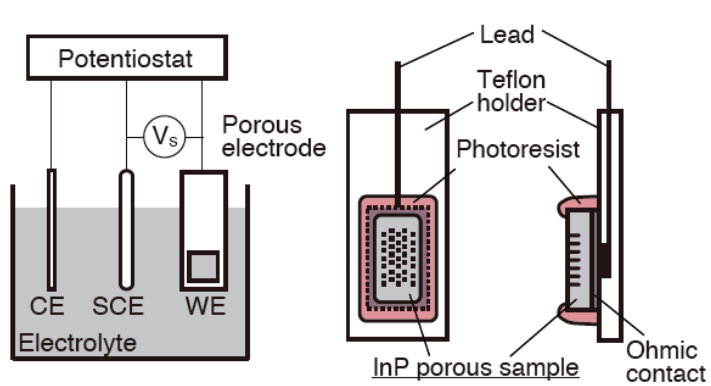

(a)

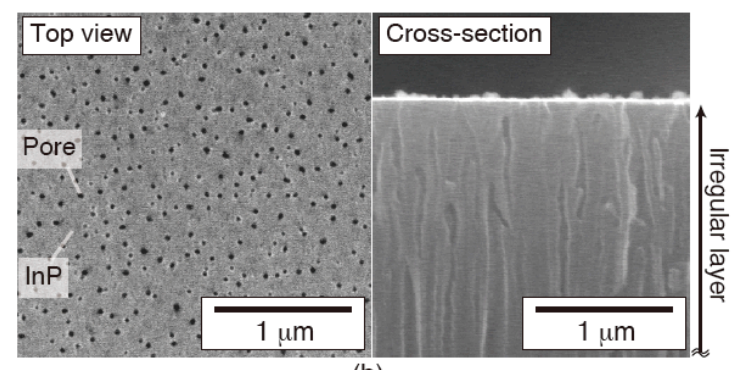

(b)

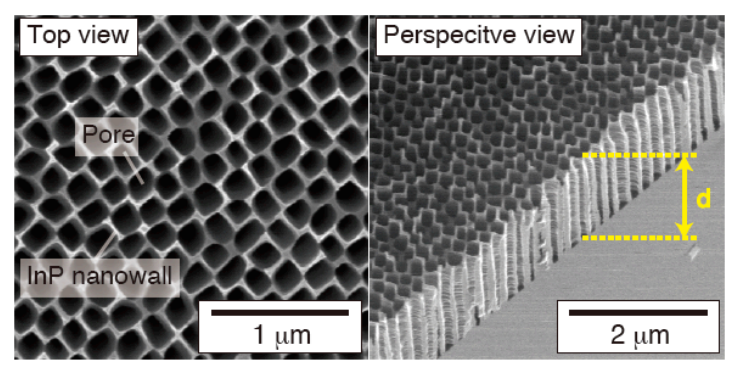

(c)

Fig. 1: Experimental setup and SEM images of InP porous samples. (a) Schematic of experimental setup. (b) InP porous sample with irregular top layer. (c) InP porous sample after complete removal of irregular top layer by PEC etching.

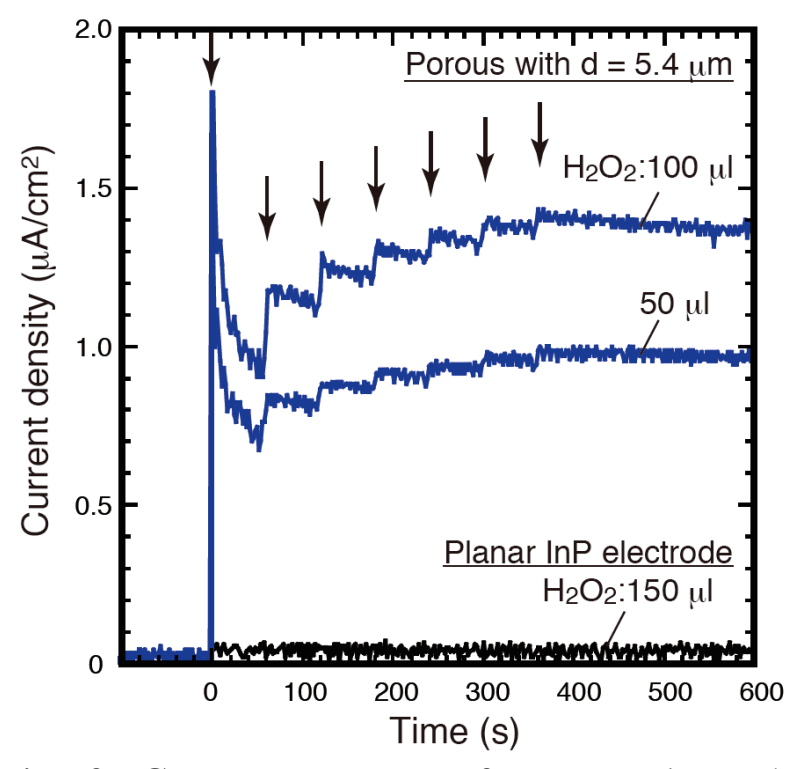

Fig. 2: Current response of porous electrode and reference planar electrode to addition of $\mathrm{H}_{2} \mathrm{O}_{2}$. Arrows indicate timing of addition of $\mathrm{H}_{2} \mathrm{O}_{2}$ into PBS electrolyte. 


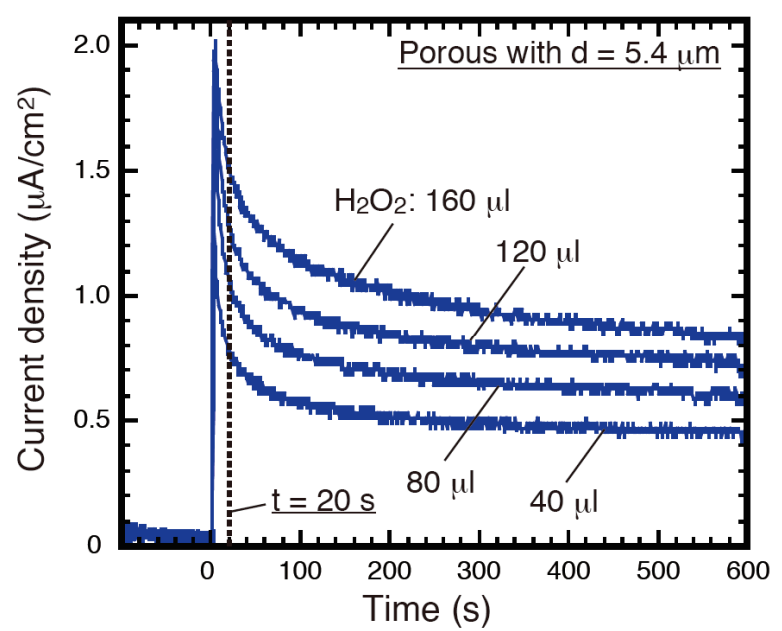

(a)

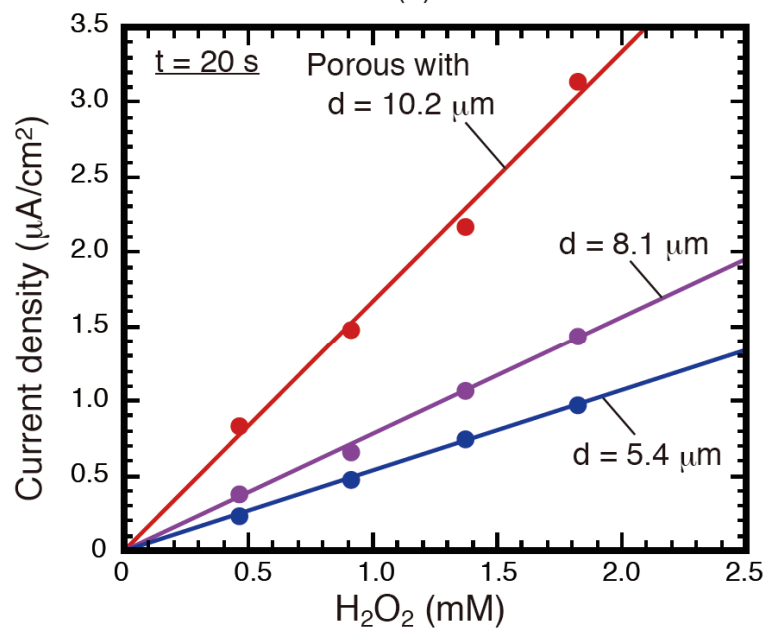

(b)

Fig. 3: (a) Transient curves of anodic currents obtained on porous electrode with pore depth, $d$, of $5.4 \mu \mathrm{m}$ with $\mathrm{H}_{2} \mathrm{O}_{2}$ only added once. (b) Calibration plots of anodic currents versus concentration of $\mathrm{H}_{2} \mathrm{O}_{2}$ for samples with various $d$ 's. Solid lines indicate fitting curves obtained by least squares approximation. 